\title{
RANCHING AND CONSERVATION OF BIRDWING AND SWALLOWTAIL BUTTERFLY SPECIES IN THE OIL PALM SYSTEMS OF PAPUA NEW GUINEA
}

BONNEAU, L J G*; ERO, M** and SAR, S*

\begin{abstract}
Despite its small size ( $<200000$ planted hectares, $0.4 \%$ of the national surface), the oil palm industry in Papua New Guinea is accused of destroying wildlife habitats, notably for iconic insects such as birdwing and swallowtail butterflies. Two subspecies of butterfly (Ornithoptera priamus bornemanni and Papilio ulysses ambiguus) endemic in West New Britain were used in a study aimed at developing a model, low-maintenance butterfly farm for conserving and propagating iconic species within the oil palm estate environment. Food sources of both the larval and adult stages were identified and investigated for their suitability to produce an abundance of butterflies. Large numbers of $\mathrm{O}$. p. bornemanni were produced when the larval food plant (Aristolochia tagala) was grown at high density. For P. u. ambiguus, the presence of specific nectar-producing plants was sufficient to attract the insect from the wild to breed in the farm. Suggestions for establishment of butterfly farms are provided and it is recommended that the oil palm industry enhance conservation of iconic butterflies by establishing butterfly farms on the estates and increasing butterfly food sources in targeted restoration and conservation areas.
\end{abstract}

Keywords: Ornithoptera, Papilio, nectar, Aristolochia.

Date received: 20 February 2019; Sent for revision: 15 March 2019; Received in final form: 9 April 2019; Accepted: 3 July 2019.

\section{INTRODUCTION}

Papua New Guinea (PNG) is home to a large variety of birdwing butterflies (Parsons, 1999), some of which live in areas that have been developed, or are under development for oil palm plantations (Miller III et al., 2011). Conversion of forest to agriculture reduces biodiversity (Bowman et al., 1990). This conversion probably includes the loss of food plants

* Dami Oil Palm Research Station, P.O. Box 165 Kimbe, West New Britain Province, Papua New Guinea.

E-mail:Ibonneau@nbpol.com.pg

** Papua New Guinea Oil Palm Research Association, P.O. Box 97 Kimbe, West New Britain Province,

Papua New Guinea. and habitat of the birdwing butterflies, thereby affecting the biodiversity of butterflies (New et al., 1995; Rundlöf and Smith, 2006). At the end of 2018, the oil palm industry in PNG was estimated to have reached about 200000 planted hectares (Bonneau et al., 2018), with a land bank about twice that size. However, the more established palm oil companies founded between 1967 and 1985 have been pioneering sustainable agricultural practices (NBPOL, 2014; SIPEF, 2017). New Britain Palm Oil Limited (NBPOL) and Société Internationale de Plantations et de Finance (SIPEF) projects are now $100 \%$ certified by the Roundtable on Sustainable Palm Oil (RSPO) and these two companies are working towards achieving the environmental and 
sustainable standards required by the Rainforest Alliance and Sustainable Agriculture Network (RA / SAN) (Wienke, 2018). The PNG oil palm industry has been accused of causing destruction of birdwing butterfly habitats (Collins and Morris, 1985; Revesz, 2017), bringing attention of the oil palm companies to the importance of conservation of endangered and iconic species such as birdwing butterflies.

In 2015, the Papua New Guinea Oil Palm Research Association (PNGOPRA), a nongovernmental organisation (NGO) financed wholly by the 100\% RSPO certified palm oil industry, proposed to its stakeholders a study to encourage the conservation of birdwing butterflies of the Ornithoptera species within reserve areas managed by the oil palm producers. Ornithoptera species are listed on the Convention on International Trade in Endangered Species of Wild Fauna and Flora Appendices I and II registering the endangered species globally (CITES, 2019). The project aimed to set up a butterfly farm for the creation of habitats that enable mass propagation of butterflies. Hutton (1985) has described some successful achievements in PNG in the past involving the Insect Farming and Trading Agency (IFTA) of PNG and a network of 500 smallholder insect farmers. In addition, New et al. (1995) demonstrated that after severe landscape change by industrial farming, it is possible to restore butterfly habitat in very degraded or modified landscapes. Thus, this present study aimed at establishing and cultivating suitable food sources for the butterflies (both larvae and adults) and providing conditions conducive for the complete development of the caterpillars in large numbers. Attention was focused on the common endemic West New Britain birdwing butterfly, Ornithoptera priamus bornemanni (Figure 1), and other swallowtail butterflies such as the endemic Papilio ulysses ambiguus (Figure 2), which occur around the oil palm systems established in PNG. Interestingly, the native New Britain birdwing butterfly is the emblem of many organisations on the island and across PNG, including the local Mosa Golf Club and the Oro provincial flag (Figure 3) representing different subspecies of birdwing butterflies. These butterflies are occasionally and seasonally spotted around housing areas bordering wildlife corridors but not in the industrial oil palm plantations. The study aimed at developing recommendations to conserve iconic butterflies in the oil palm conservation corridors for all the PNGOPRA members around PNG (Figure 4). The hypothesis for the study was that through the protection and establishment of habitats suitable for butterflies (i.e. a butterfly farm within the estates), including nectar-producing plants to feed the adults, host plants to provide sites for oviposition, and large amount of forage for the caterpillars, the wild population could be boosted by increasing the success of breeding and rearing in large numbers of the targeted insects. Recommendation for PNGOPRA members would be based on this study.

\section{MATERIALS AND METHODS}

The study was conducted at the Dami Oil Palm Research Station (OPRS), located on the northern coast of the island of New Britain in the province of West New Britain. A site was selected in the Dami OPRS residential area where plants were established for the trial (S 553'14" E150 $33^{\prime} 56^{\prime \prime}$ ).

To attract and proliferate O. p. bornemanni, a garden of gliricidia trees (Gliricidia sepium) associated with pipe vine (Aristolochia tagala), the

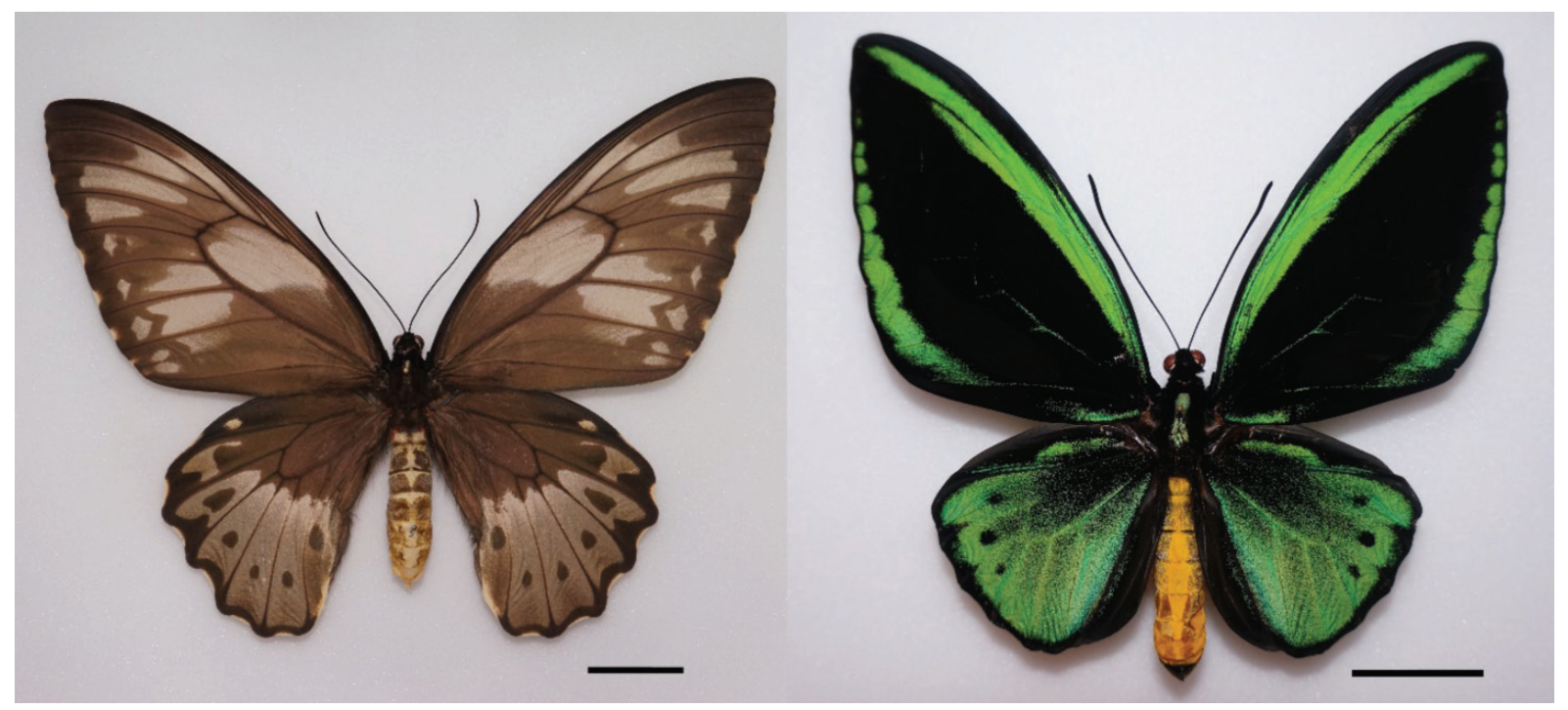

Figure 1. Framed Ornithoptera priamus bornemanni produced in Dami butterfly farm in 2017. Left is a female specimen, and right is a male specimen. Scale bar $=20 \mathrm{~mm}$. 


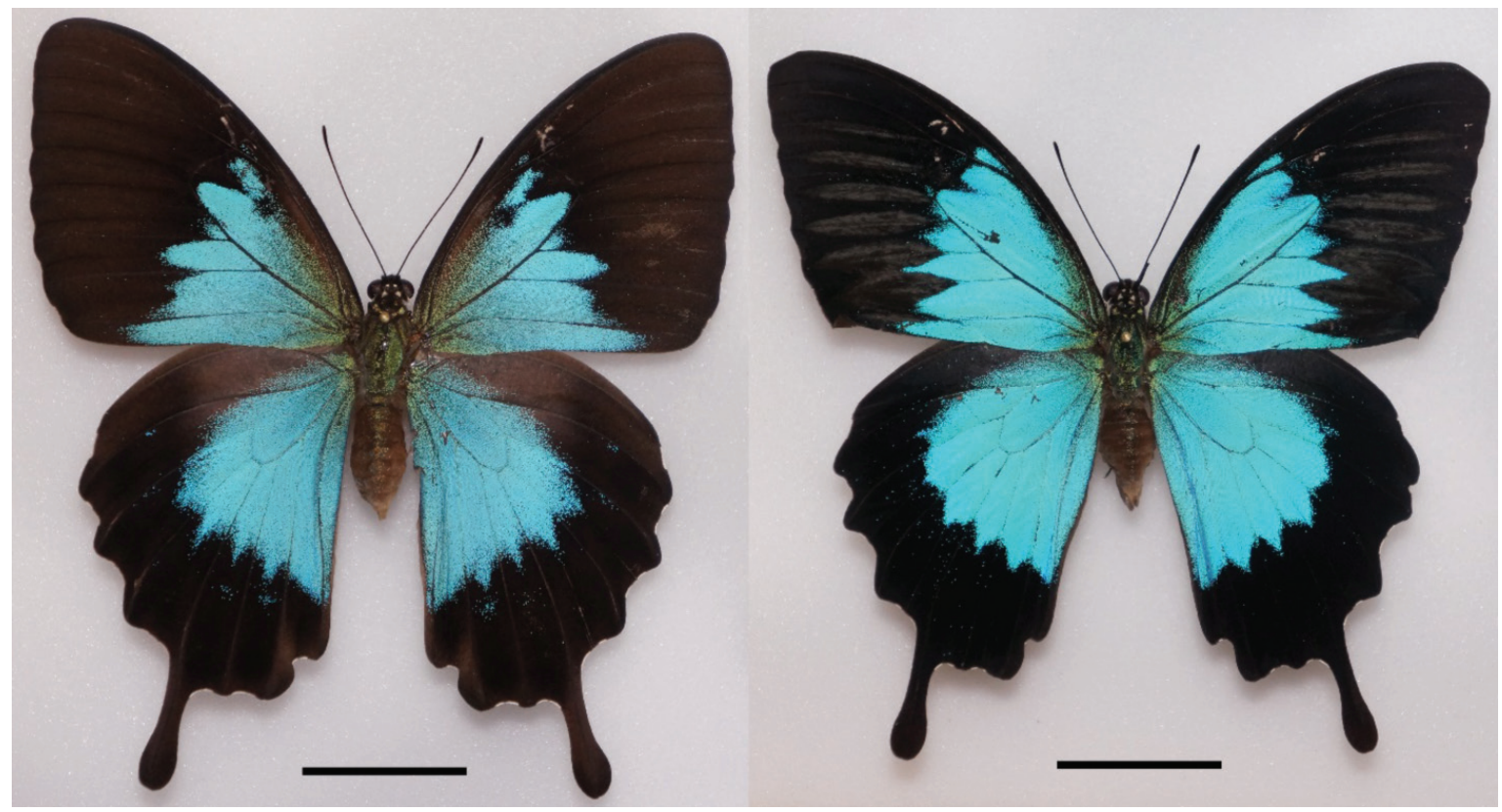

Figure 2. Framed Papilio ulysses ambiguus produced in the Dami butterfly farm in 2017. Left is a female specimen, and right is a male specimen. Scale bar $=20 \mathrm{~mm}$.
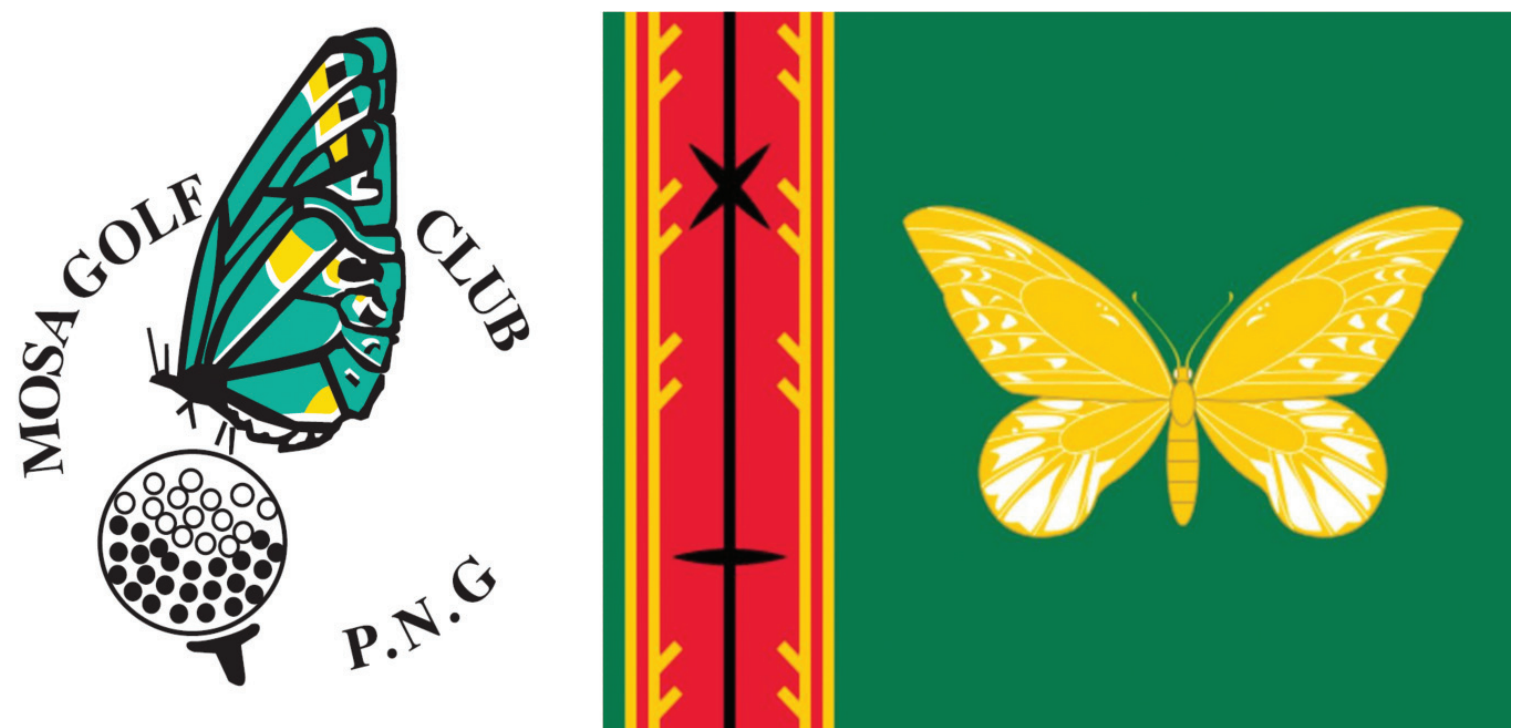

Figure 3. West New Britain Mosa Golf Club logo and Oro provincial flag, representing a birdwing butterfly.

main food plant of the birdwing butterfly larvae, was established. In January 2016, $60 \mathrm{~cm}$ long cuttings of G. sepium were planted $(20 \mathrm{~cm}$ into the ground) at different densities ranging from 2, 4, 8 and 16 trees per $100 \mathrm{~m}^{2}$. Gliricidia sepium was chosen as a fast-rooting and fast-growing tree that is propagated locally from cuttings and coppiced for fire wood. Seeds of $A$. tagala were harvested from the wild and germinated in seedling trays. The trays were filled with a $2 \mathrm{~cm}$ layer of river sand and the seeds were sprinkled over the sand. The trays were placed under shade in a well-ventilated area and kept moist, but not soaked. Germination was observed two weeks later and the young vigorous seedlings were transplanted in the butterfly garden a month later (a year after the G. sepium cuttings had been planted during the rainy season and had formed a dense canopy). The root stocks of the vines were protected using coconut husks, and the vines were trained on twigs to reach the branches of the supporting G. sepium trees. The combination of a G. sepium tree with an $A$. tagala vine is referred to below as an 'A/G plant pair'. A total of $60 \mathrm{~A} / \mathrm{G}$ plant pairs were established in the trial replicating each density twice, thus covering an area of $800 \mathrm{~m}^{2}$ for the $\mathrm{A} / \mathrm{G}$ plant pairs. A border of nectar-producing plants was planted around the butterfly garden at the same time as the G. sepium cutting were planted, 


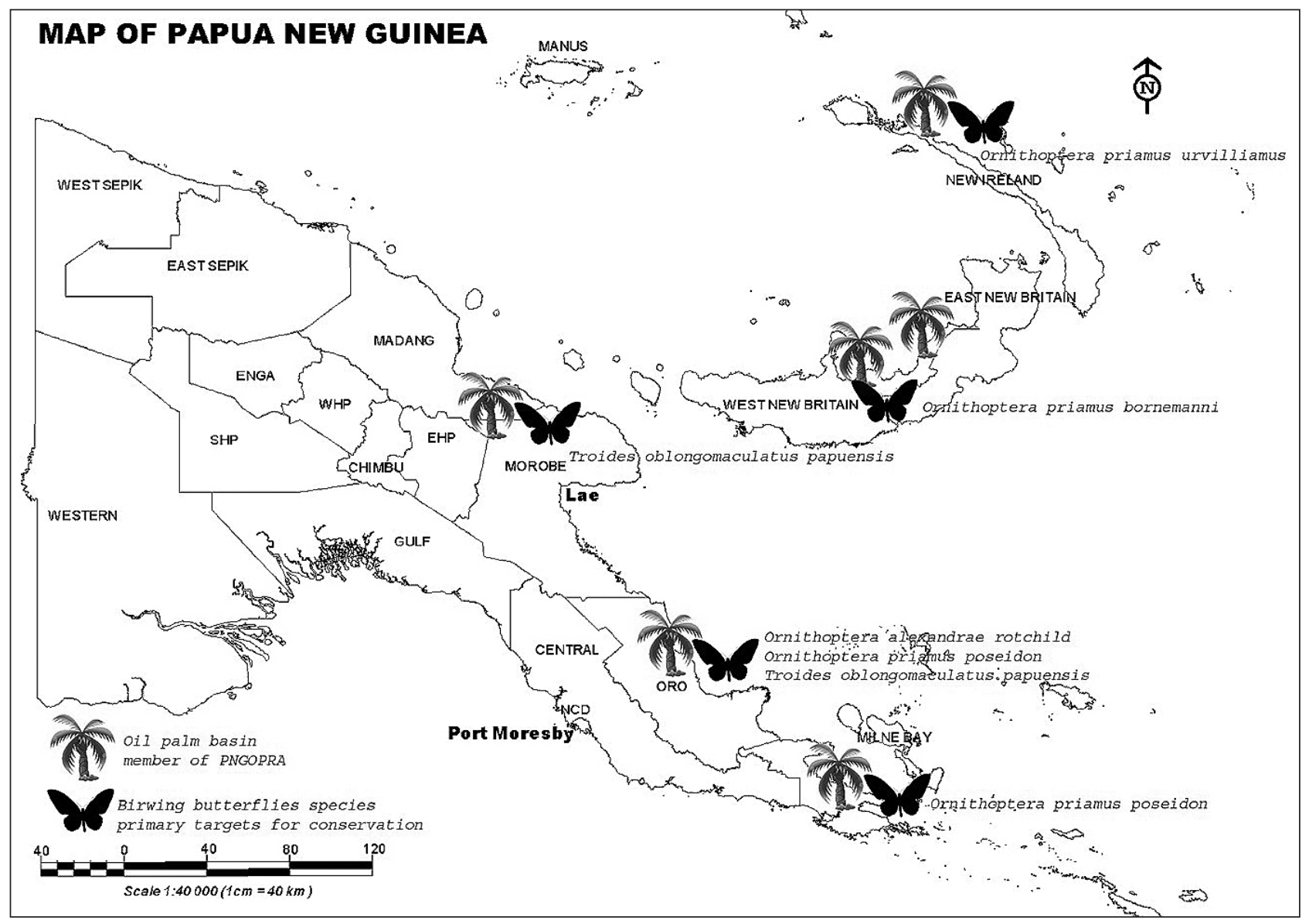

Figure 4. Map of Papua New Guinea Oil Palm Research Association (PNGOPRA) members and species of iconic endemic birdwing butterflies in their vicinity.

to provide nectar sources for the adult butterflies. The set of nectar-producing plants were chosen for having been observed to be visited by birdwing butterflies, for their ease of propagation from cuttings and also for their long-lasting almost continuous flowering season. These included the red or orange large-leaf Ixora coccinea, the red or orange mediumleaf Ixora coccinea, red, orange and yellow small-leaf Ixora coccinea, red, orange or pink Hibiscus spp., and pagoda (Clerodendrum paniculatum) (Figures 5 and 6). To establish sugar concentration in the flowers, 10 individual flowers per flower variety from different plants were sampled using a micropipette on a clear, dry day between 7 am and 8 am, before insect activities start. The sugar concentration of collected nectar from these plants was measured using a medical glucometer to determine whether there was any influence of sugar (glucose) content on preference for food source by the butterflies.

The number of pre-adult O. p. bornemanni specimens for each A/G plant pair was observed and recorded on a weekly basis between December 2016 and September 2017. Recording of visits by adult O. p. bornemanni on nectar-producing plants was performed twice a week for a period of two months from 2 May 2017 to 6 July 2017.
To attract and propagate $P . u$. ambiguus, adults were observed and found ovipositing on two host plants, which were later found to be suitable food sources for their caterpillars. One was the shrub Euodia hortensis and the other was the rainforest tree Melicope elleryana (syn. Euodia elleryana), commonly known as pink-flowered dogwood. Euodia hortensis and M. elleryana were propagated from seed, and seedlings of both plants were planted in the surrounds of the butterfly farm.

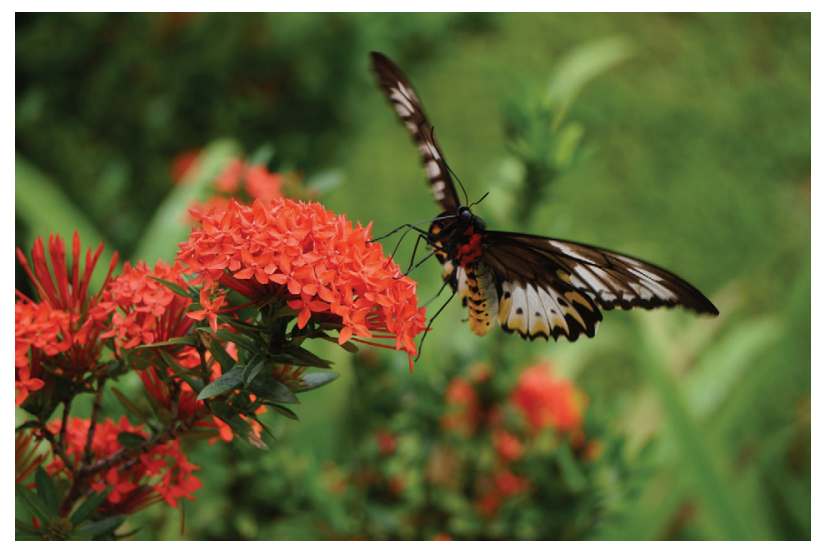

Figure 5. Female Ornithoptera priamus bornemanni feeding on red small-leaf Ixora coccinea flowers. 


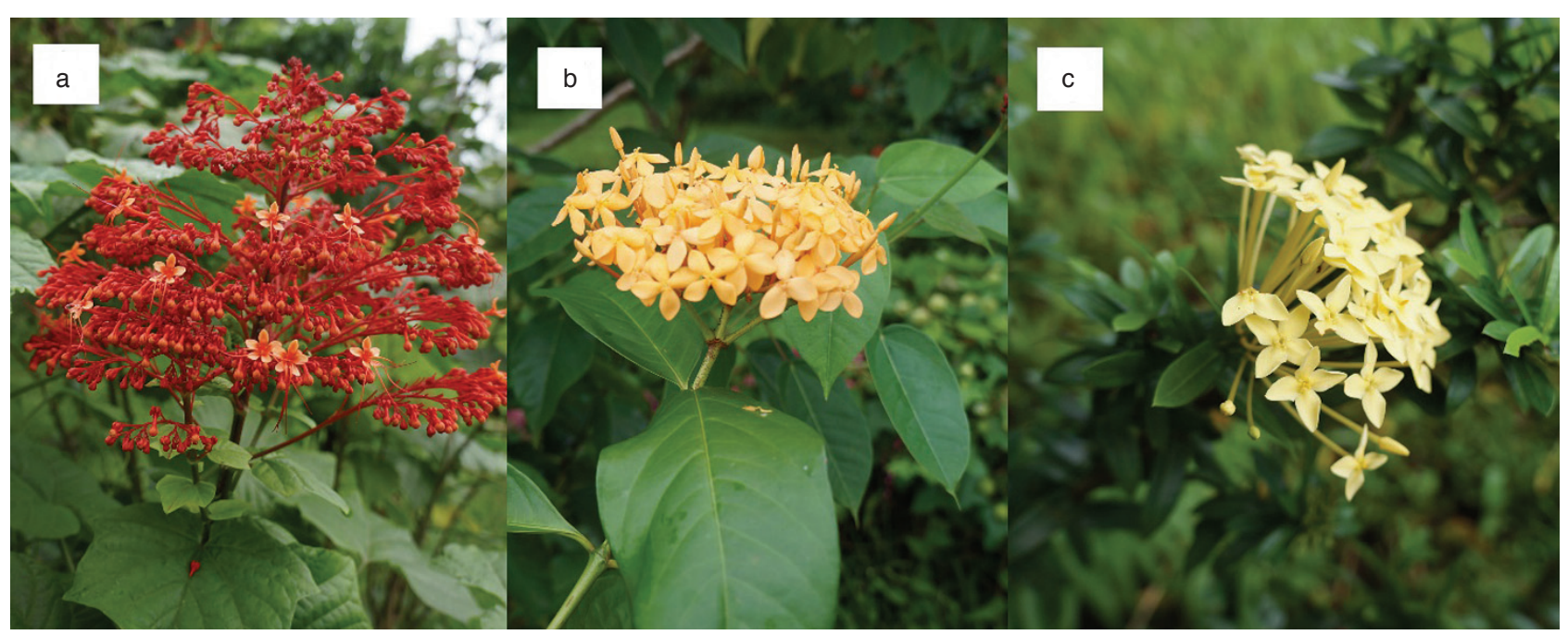

Figure 6. Examples of some nectar-producing plants grown in this study. (a) Clerodendrum paniculatum, (b) orange large-leaf Ixora coccinea and (c) yellow small-leaf Ixora coccinea.

\section{RESULTS}

All G. sepium cuttings established successfully, and two to three shoots growing from the upper part of the cutting were left to develop as leaders. The shoots were pruned at $1 \mathrm{~m}$ and developed in a dense canopy of 6-9 shoots per root stock (Figure 7a).

Seeds of $A$. tagala were collected from seed pods in the wild. The germination rate was very high $(>60 \%)$ when sprinkled on wet river sand and kept moist under shade. Young seedlings were easily transplanted in 1 litre nursery bags and left to grow to about 50 to $100 \mathrm{~cm}$ long, five months after sowing, before being transplanted next to the $G$. sepium trees and trained on a twig to climb the tree (Figures $7 a$ and $7 b$ ).

Records of adult O. p. bornemanni visits to the nectar sources indicated that peak flights occurred in the morning and late afternoon. Adults made few visits during the day between 10 am and 2 pm (Figures 8 and 9). It was not possible to record whether there were the same butterflies visiting the garden in the morning and afternoon and days after days. In the case of the nectar-producing plant I. coccinea, which has several varieties with different leaf sizes, the varieties with larger leaves were significantly visited more often, and the number of visits diminished with decreasing leaf size (Figure 8). Furthermore, for the medium- and small-leaf varieties, the red-flowered I. coccinea was more attractive than the orange-flowered variety (Figure 8). No visits were recorded on yellow I. coccinea for the duration of the experiment (data not shown).

In the case of Hibiscus spp., Figure 9 indicates that the red-flowered varieties are more attractive than the orange- and pink-flowered varieties. Clerodendrum paniculatum was visited less in the mornings than the red and orange Hibiscus varieties, but had comparative number of visits in the late afternoon. However, the Hibiscus spp. and C. paniculatum were significantly less visited than the $I$. coccinea varieties.

The sugar concentration of nectar collected from flowers of the Hibiscus spp. varieties was significantly higher than nectar collected from $I$. coccinea and C. paniculatum flowers (Figure 10). However, it is important to note that Hibiscus spp. varieties have large, single flowers, while I. coccinea varieties and C.paniculatum have inflorescences with multiple flowers (Figure 6). The number of flowers per inflorescences is presented in Figure 11 and indicates that the inflorescences with most numerous numbers of flowers (red- or orangeflowered large-leaf $I$. coccinea varieties) were visited the most by O. p. bornemanni adults (Figure 8). By combining the mean number of flowers and nectar concentration, it appears that O. p. bornemanni may adopt a strategy of visiting the largest red/orange flowers that maximise its sugar intake per visit.

Figure 12 presents the pre-emergence stages of O. $p$. bornemanni recorded on the entire butterfly farm. The data recorded weekly are presented as mean occurrence of individuals per A/G plant pair per week, for a given month of either four or five weeks. Observations showed that the oviposition was detectable in January 2017, with a peak in February to March, gradually decreasing from April to July, and below detection from August onwards (Figure 12). A few first instars were detected in December, thereafter following the same pattern as the eggs, with the largest population obtained between February and May 2017.

The second and third instars followed similar patterns with peak periods in March and May 2017. The number of pupae remained fairly constant during the first eight months of the study, 


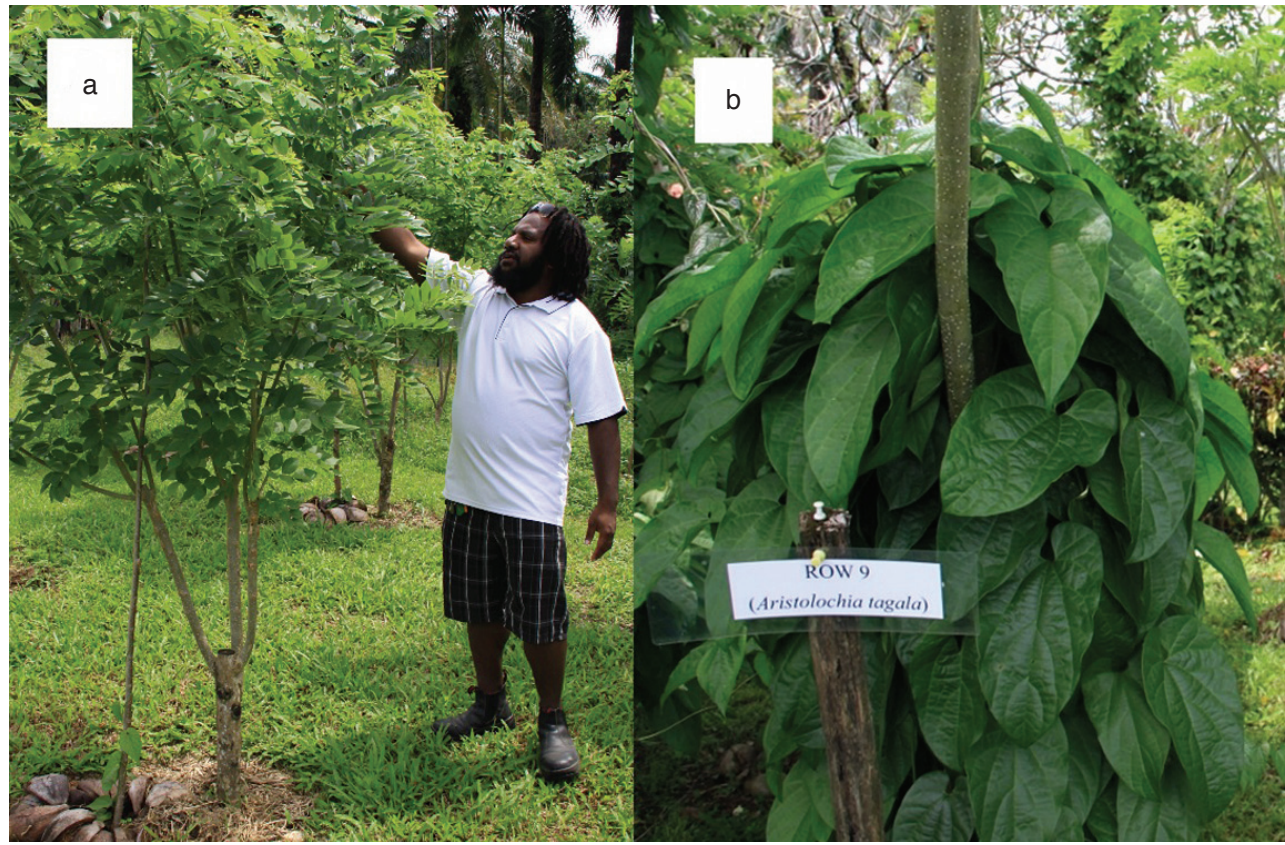

Figure 7. (a) Solomon Sar inspecting one-year old Gliricidia sepium trees paired with a two-month old Aristolochia tagala seedling and (b) leaves of fully grown Aristolochia tagala vine.

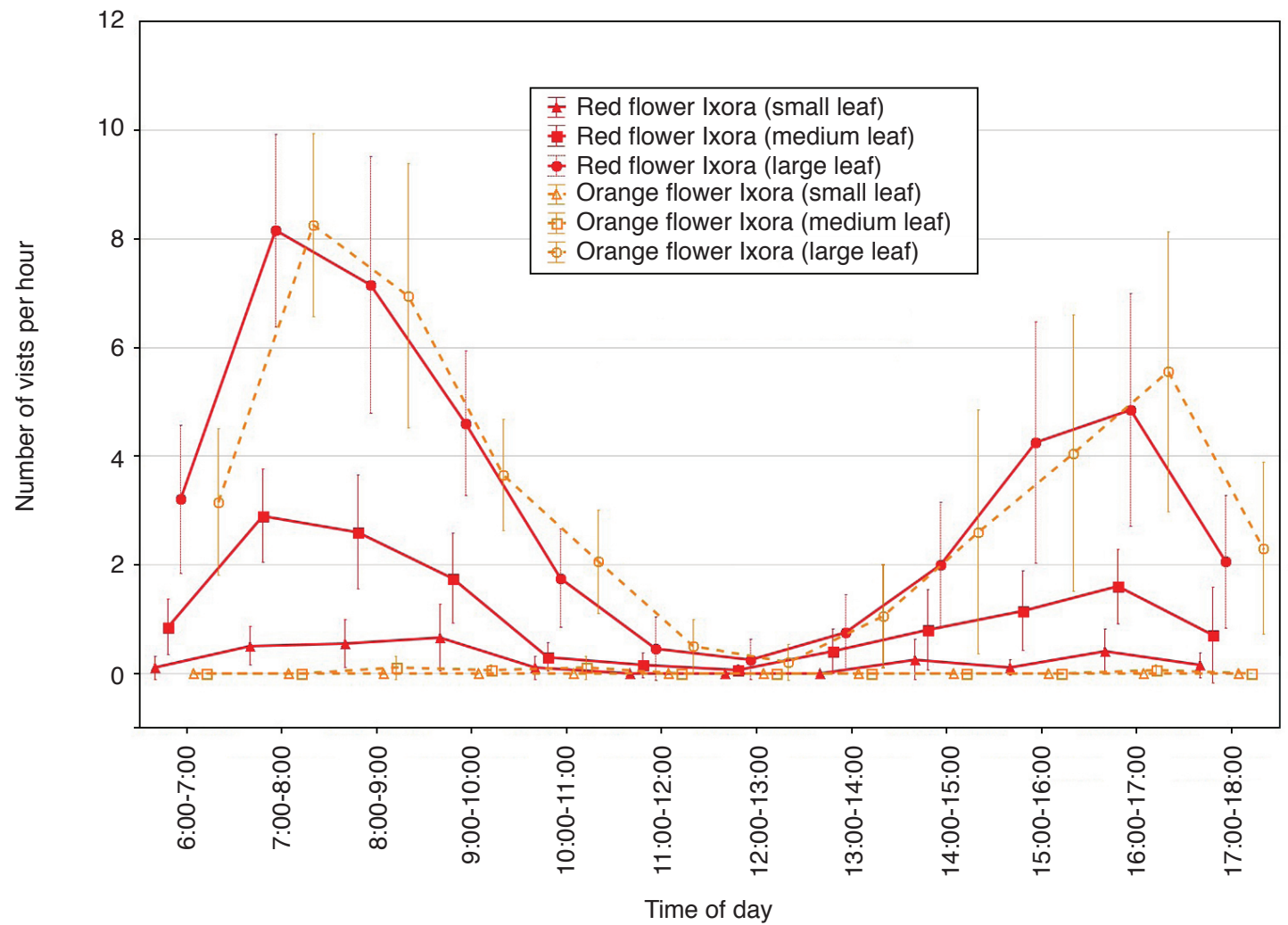

Figure 8. Number of visits per hour by Ornithoptera priamus bornemanni adults on six varieties of Ixora spp. between 2 May 2017 and 6 July 2017. Symbols represent the mean \pm 0.95 confidence interval.

and collapsed in August 2017. Parasitism of the larvae and pupal stages and subsequent mortality were observed; parasitism was more important during the wet weather which generated some waves of mortality amongst the larvae and pupae. Nonetheless, with the project having $60 \mathrm{~A} / \mathrm{G}$ plant pairs, up to 20 new first instars were produced per week at its peak, and four new pupae were found per week throughout the eight month breeding season.

From analysis of the population density per planting density for the immature stages (Figure 


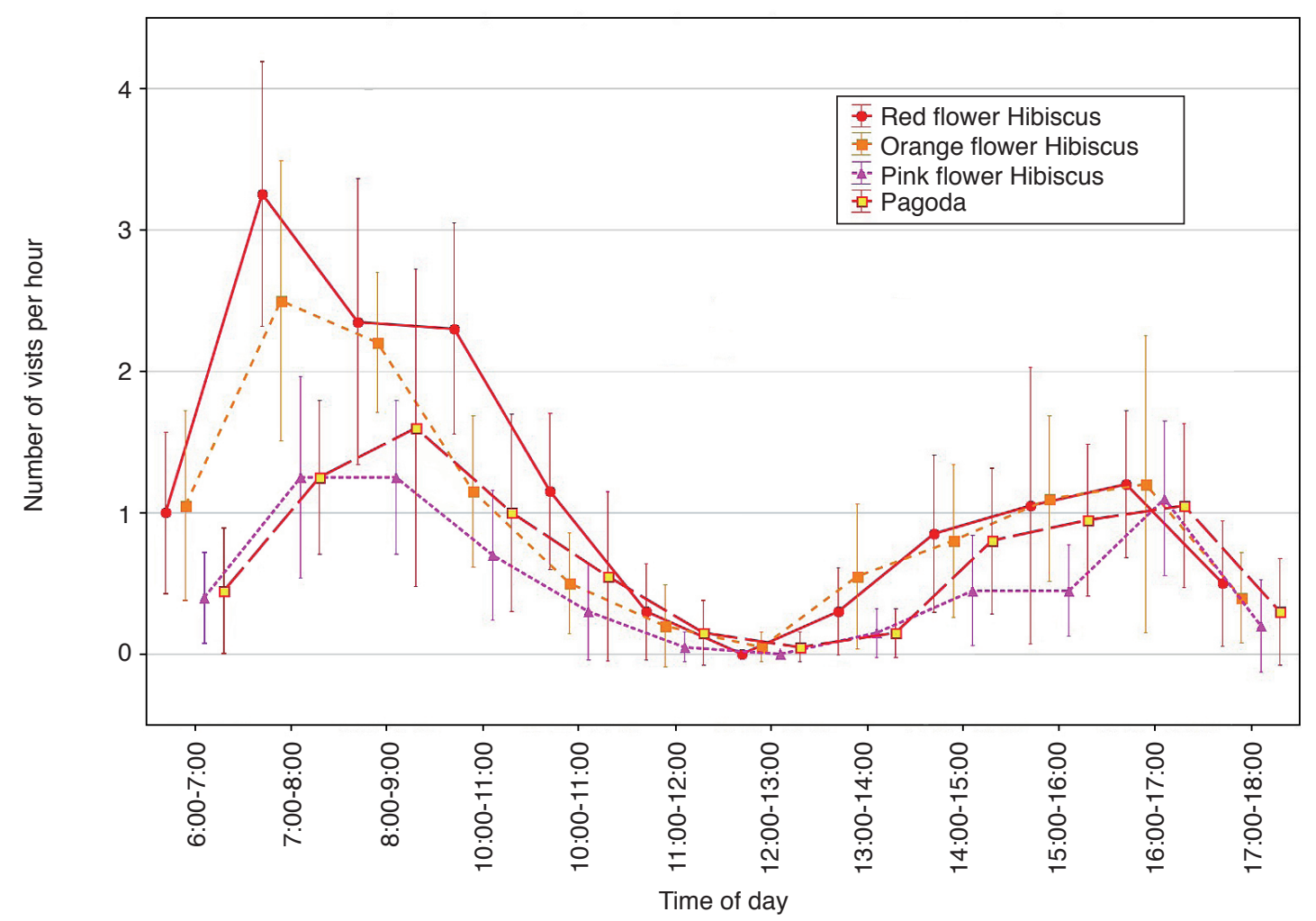

Figure 9. Number of visits per hour by ornithoptera priamus bornemanni adults on three varieties of Hibiscus spp. and

C. paniculatum (pagoda) between 2 May 2017 and 6 July 2017. Symbols represent the mean \pm 0.95 confidence interval.

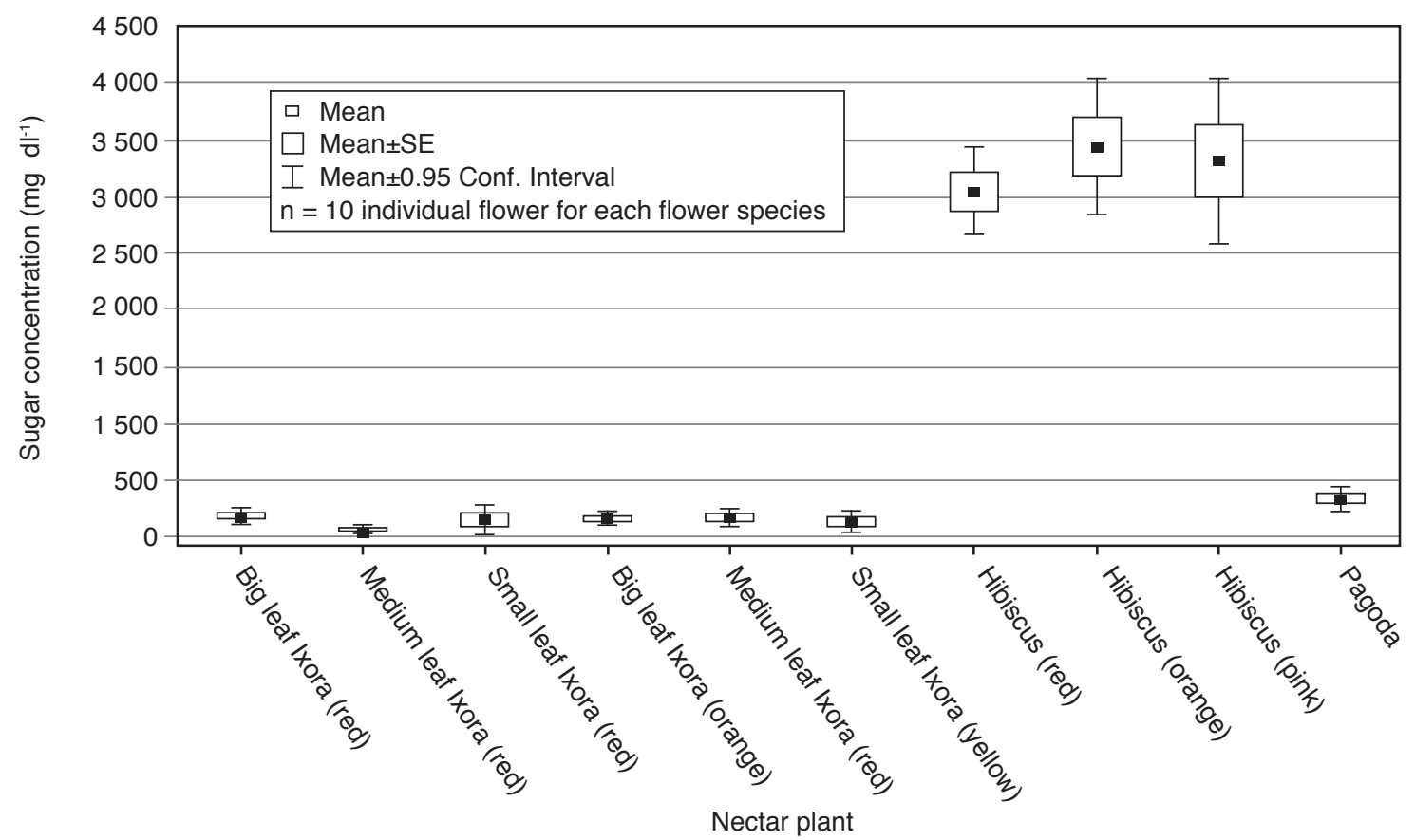

Figure 10. Nectar sugar concentration per flower from 10 nectar sources including Ixora spp., Hibiscus spp. and C. paniculatum (pagoda) (recorded in August 2018). Symbols represent the mean \pm 0.95 confidence interval, $n=10$ for each flower species sampled at 7 am.

13), it is evident that O. p. bornemanni favoured the high density planting for oviposition. The density of 16 trees per $100 \mathrm{~m}^{2}$ produced nearly 10 first instars per $\mathrm{A} / \mathrm{G}$ plant pair, of which a third reached pupal stage over the span of the observation period. Furthermore, fewer eggs and instars were observed on the lower density planting of $\mathrm{A} / \mathrm{G}$ plant pairs, with a lower success rate of conversion to the pupal stage. It was deduced from this observation that shading and high availability of food source are the main contributing factors to the high number of individuals produced. 


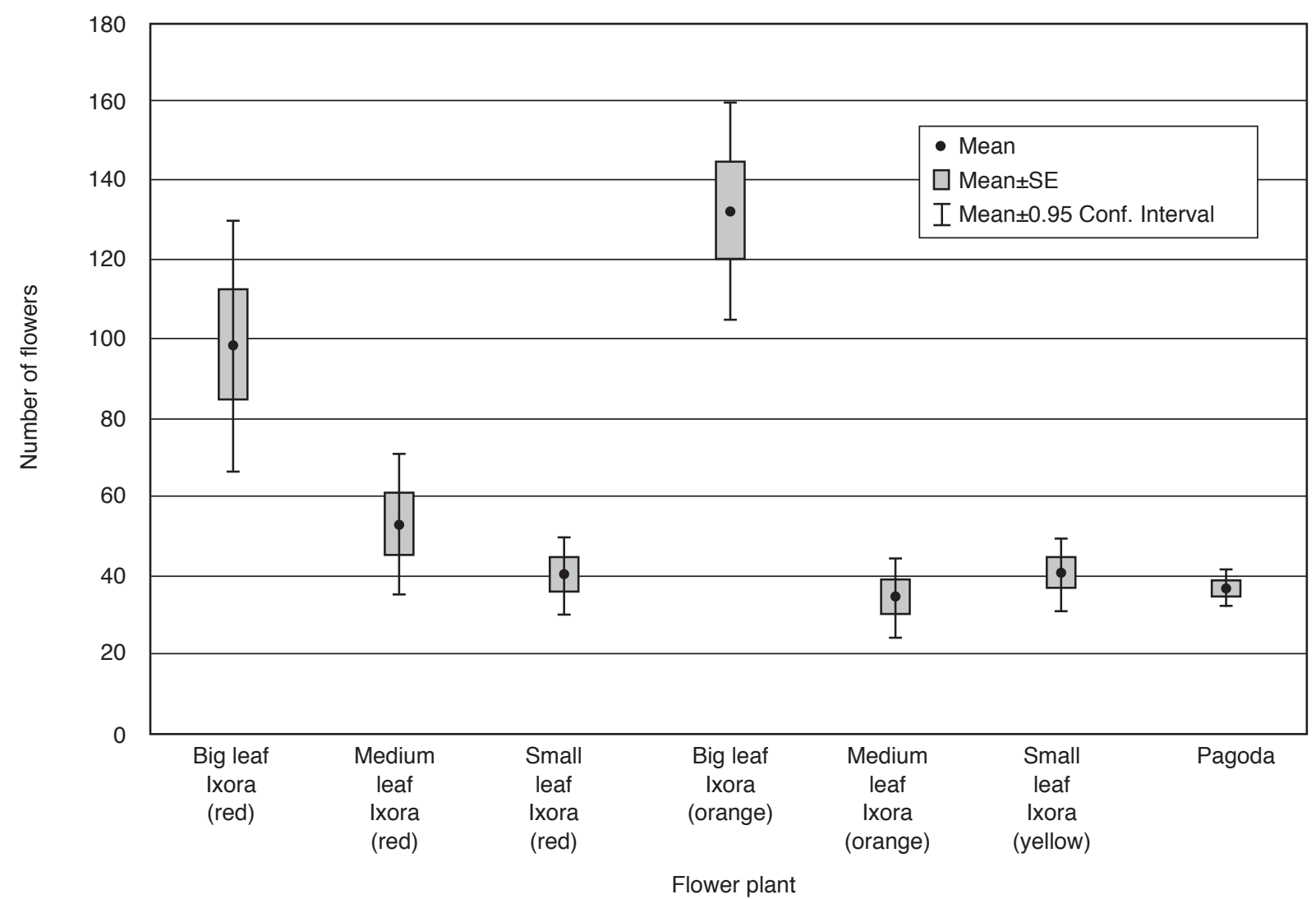

Figure 11. Number of flowers recorded on inflorescences of seven nectar-producing plants. Symbols represent the mean \pm 0.95 confidence interval.

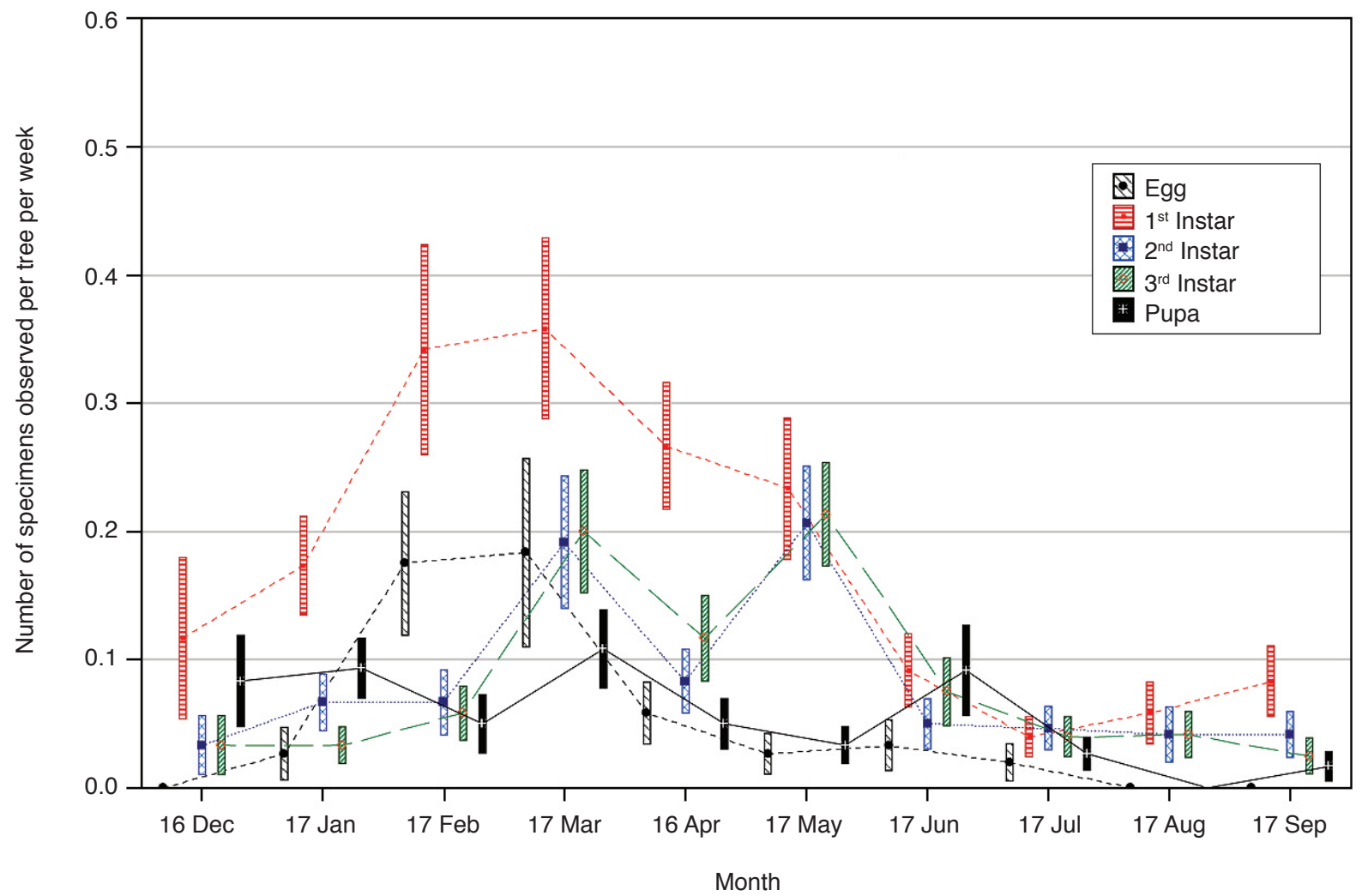

Figure 12. Mean numbers of Ornithoptera priamus bornemanni specimens at different stages (egg, $1^{\text {st }}$ instar, $2^{\text {nd }}$ instar, $3^{\text {rd }}$ instar or pupa) observed per G. sepian tree with an A. tagala plant pair between December 2016 and September 2017. Symbols represent the mean from weekly observations (mean per month), and the box indicates the standard error. 
The mortality at the pupal stage was mainly caused by parasitism and was observed at a rate of $10 \%$, independent of the host plant density. As such, the planting density at $16 \mathrm{~A} / \mathrm{G}$ plant pair per $100 \mathrm{~m}^{2}$ also produce the highest number of adult butterflies with about 50 individuals per $100 \mathrm{~m}^{2}$ per season (Figure 13).

Although the plants of E. hortensis and $M$. elleryana were less than one-year old at the time of the study, it was observed that they attracted some $P$. $u$. ambiguus butterflies to breed and complete their life cycle. This was a remarkable achievement since $P$. $u$. ambiguus is usually less common than O. p. bornemanni. Nonetheless, it was seen in large numbers throughout the year of this study, and has been present in gardens at Dami OPRS since.

\section{DISCUSSION AND RECOMMENDATIONS}

The study demonstrates that desired butterfly species can be farmed in small areas and large number of individuals can be produced by attracting adults from natural areas to suitable breeding sites. This strategy concurs with the initiative led by Hutton (1985), and was shown to be a successful approach for this study on O. p. bornemanni and P. u. ambiguus. Birdwing butterflies are iconic in the whole of PNG and conservation efforts should primarily address the conservation of those species. In the case O. p. bornemanni, the larval food source needs to be established at high density to offer good shading protection. The dense vegetation not only protects caterpillars and pupae from predators such as birds, but also from intense radiation. It is recommended that the larval food sources, such as the pipe vine, are propagated through seeds since this is easy to do and ensures that the genetic diversity of the host plant is maintained. Indeed, it was observed that some female O. p. bornemanni adults favoured certain seedlings of A.tagala and disregarded others (for no obvious reasons), and it could be anticipated that such unapparent preferences may be observed for the other butterflies. This led to the consideration that female butterflies may have a range of attractiveness to their food sources and oviposition sites.

For establishment of suitable 'butterfly gardens' for the birdwing butterfly, young pipe vines should be planted near plants presenting thin stems and branches that they can climb and eventually reach the canopy, or alternatively, the young vines can be trained to reach the top of the trees. While large leaves appeared more attractive in Ixora subspecies over the colours red and orange. It was noted that there was a direct correspondence between

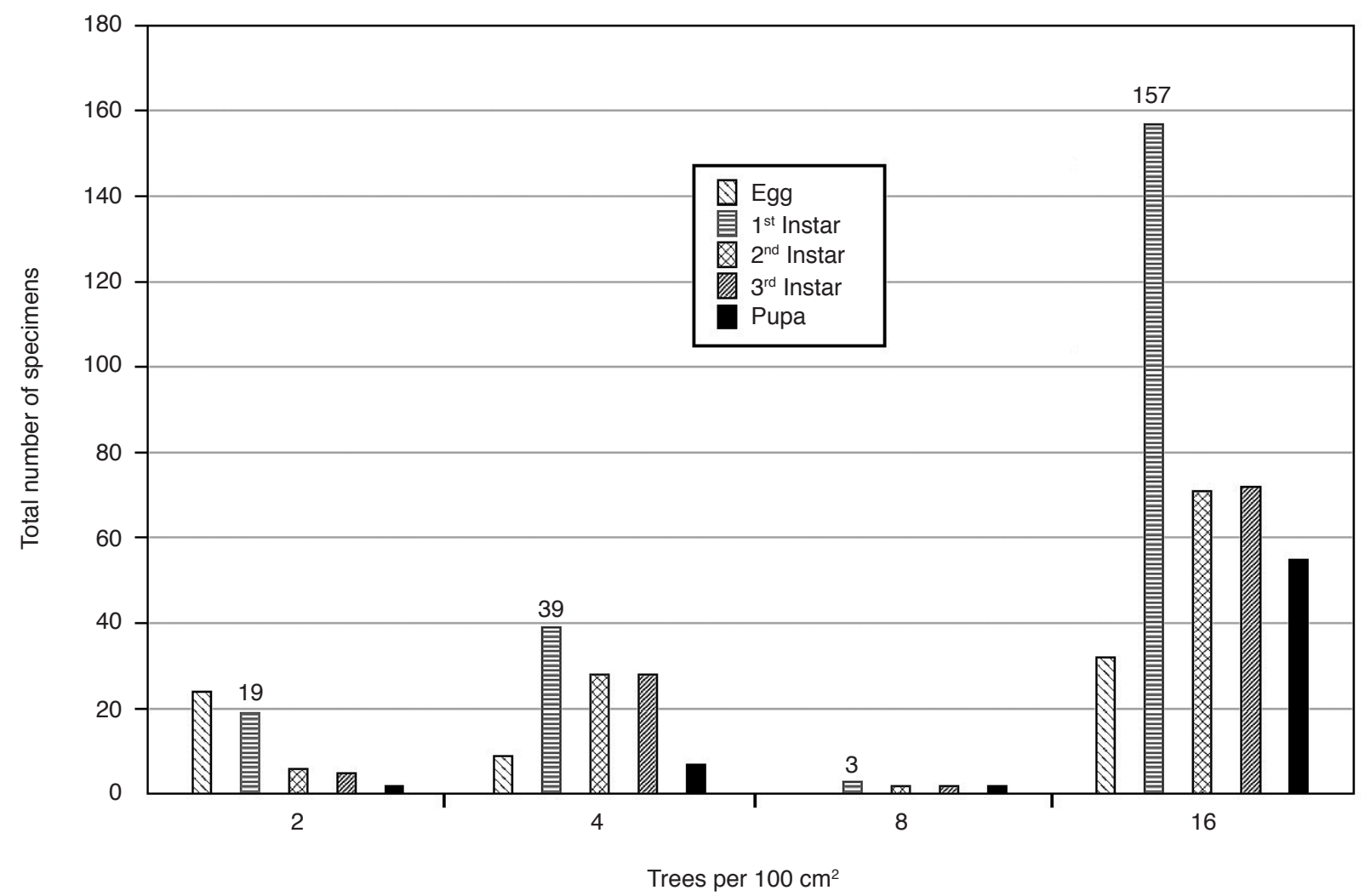

Figure 13. Total number of Ornithoptera priamus bornemanni individuals (for different life stages) at different planting densities of G. sepian tree with an A. tagala plant pairs, between December 2016 and September 2017. Values are mean of two replicates. 
leaf size and inflorescence size. As such, it may also mean that the inflorescence size is the most influential factor. Nectar-producing plants with large inflorescences with red- or orange-coloured flowers should be chosen and planted near or in the border of the restoration or conservation areas to attract nearby adults to the growing pipe vines. In addition to the nectar-producing plants used in this study, we also noted the butterflies feeding on flowers of the kwila tree (Intsia bijuga), which is a native tree of South-east Asia that is severely under pressure from logging due to its high value timber (Rundlöf and Smith, 2006; Areki and Cunningham, 2010; Lamb, 1977).

Insects generally have the propensity to thrive under the correct environmental conditions, i.e. an abundance of food sources for all stages of the life cycle combined with suitable climate, with food abundance generally being the determining factor in reaching their field capacity (Dethier and MacArthur, 1964). In oil palm agricultural systems where sustainable practices are desired, there are often, throughout the course of land development and replanting activities, vast areas of vegetation to conserve and to restore as natural habitats. During that process, the conservation of birdwings, swallowtails and other butterflies can be achieved in small managed areas which can be regarded as hotspots for the production of butterflies which can later explore larger areas and populate the environment.

Miller III et al. (2011) gave a list of a great range of food sources of the larval stages of many butterflies endemic to PNG. As part of its restoration and conservation programmes, the oil palm industry has the capacity to propagate a wide range of such plants in their nurseries. In targeted areas, biodiversity inventories of available food sources for the entire life cycle of the butterflies could determine the missing or rare plants which are critical to the life cycle completion of some butterfly species. Plants propagated from seeds in nurseries can then be reintroduced and nurtured over time until the ecosystem becomes conducive for the different host plant species in the different layers of the reforested areas to naturally thrive and provide sustainable habitats for many butterfly species.

To establish a baseline on the animal requirements, conducting live observations of feeding habits and of the making of preferred habitats has to be conducted. Replication and enlargement of preferred habitats and its attributes aimed at boosting the level of reproduction and therefore enhance conservation efforts in raising population levels. Lastly, this study indicates to other organisations that approachable conservation effort of endangered animals can be performed even at small scales.

\section{CONCLUSION}

Conservation projects commanded by the oil palm industry often focus on large mammals but PNG is host of none. Nonetheless, PNG has a very high biodiversity of which some birdwing and swallowtail butterflies species ought to be protected and conserved. The study demonstrates that the oil palm industry in PNG and elsewhere have a lowcost opportunity to conserve endangered insect species such as birdwing and swallowtail butterflies. The type of butterfly garden recommended in this study is one example of how active establishment of host plant in rather small area can have a significant impact on wild population of insects. The study should motivate the PNG oil palm industry stakeholders to actively develop conservation projects aiming at conserving known organisms. The authors of this article are now collaborating on a new project aiming at the conservation of the Queen Alexandra's Bird Wing Butterfly (QABB, Ornithoptera alexandrae) in Oro province in PNG and is solely sponsored by one oil palm industry player and assisted by one conservation trust (BBC, 2017).

\section{ACKNOWLEDGEMENT}

The authors would like to thank the sponsors of the study, NBPOL, SIPEF and their associate smallholder farmers. We would like to thank Simon Makai and Ricky Uker, as well as the other entomology team members for their observations and valuable guidance throughout the duration of the study. Tabitha Manjobie is also acknowledged for her assistance with the sugar concentration measurements, and Dr Marnie Light for her valuable input in reviewing the manuscript. Finally, the visitors of Dami OPRS butterfly farm are also thanked for their encouragement and support.

\section{REFERENCES}

Areki, F and Cunningham, A B (2010). Fiji: Commerce, Carving and customary tenure. Wild Governance-finding Policies that Work for Non-timber Forest Products. Earthscan, London. p. 229-242.

BBC (2017). Swallowtail butterfly could benefit from Papua New Guinea project. https://www. bbc.com / news / av / uk-england-norfolk-41532988/ swallowtail-butterfly-could-benefit-from-papuanew-guinea-project\#, accessed on 11 February 2019.

Bonneau, L J G; Banabas, M; Ero, M M; Pilotti, C and Nake, S (2018). PNGOPRA Annual Report 2017. Dami Research Station, PNG. 76 pp. 
Bowman, D M; Woinarski, J; Sands, D; Wells, A and Mcshane, V (1990). Slash-and-burn agriculture in the wet coastal lowlands of Papua New Guinea: Response of birds, butterflies and reptiles. J. Biogeography, 17(3): 227-239.

CITES (2019). The CITES Species. https: / / www.cites. org/eng/disc/species.php, accessed on 15 February 2019.

Collins, N M and Morris, M G (1985). Threatened Swallowtail Butterflies of the World: The IUCN Red Data Book. IUCN, Gland \& Cambridge. 401 pp.

Dethier, V and Macarthur, R H (1964). A field's capacity to support a butterfly population. Nature, 201: 728.

Hutton, A F (1985). Butterfly farming in Papua New Guinea. Oryx, 19: 158-162.

Lamb, D (1977). Conservation and management of tropical rain-forest: A dilemma of development in Papua New Guinea. Environmental Conservation, 4: 121-129.

Miller III, D G; Lane, J and Senock, R (2011). Butterflies as potential bioindicators of primary rainforest and oil palm plantation habitats on New Britain, Papua New Guinea. Pacific Conservation Biology, 17: 149-159.
NBPOL (2014). Sustainability Report 2012/13. Kimbe: New Britain Palm Oil Limited.

New, T; Pyle, R; Thomas, J; Thomas, Cand Hammond, P (1995). Butterfly conservation management. Annual Review of Entomology, 40: 57-83.

Parsons, M (1999). The Butterflies of Papua New Guinea: Their Systematics and Biology. Academic Press London. $736 \mathrm{pp}$.

Revesz, R (2017). World's biggest butterfly in danger of extinction due to palm oil industry. Independent (26 September 2017).

Rundlöf, M and Smith, H (2006). The effect of organic farming on butterfly diversity depends on landscape context. J. Applied Ecology, 43: 1121-1127.

SIPEF (2017). SIPEF Company website. http:// www.sipef.be, accessed on 29 July 2017.

Wienke, B (2018). Rainforest Alliance celebrates conservation leadership through innovative partnerships. Rainforest Alliance (online). Rainforest Alliance. https: / / www.rainforest-alliance.org/ press-releases/gala-2018, accessed on 4 February 2019. 